\title{
Diabetic Foot Care Practice and its Associated Factors among Type 2 Diabetes Mellitus Patients Attending Primary Health Clinics in Kuantan, Malaysia: A Cross Sectional Study.
}

\author{
Azmi $\mathrm{NH}^{a}$, Abdul Hadi $A^{a}$, Md Aris $M A^{a}$, Nasreen $\mathrm{HE}^{b}$, Che-Ahmad $A^{c}$ \\ ${ }^{a}$ Department of Family Medicine, International Islamic University Malaysia \\ bepartment of Community Medicine, International Islamic University Malaysia \\ 'Department of Orthopaedics, Traumatology and Rehabilitation, International Islamic University Malaysia
}

\section{ABSTRACT}

INTRODUCTION: One of the most important and debilitating complication of diabetes mellitus is foot problem such as ulcers, infections and amputations. However, these complications are preventable by simple intervention such as regular foot care practice. This study aims to assess the foot care practice and its associated factors among type 2 diabetes mellitus patients attending primary health clinics in Kuantan. MATERIALS AND METHODS: This was a cross-sectional study conducted at four primary health clinics in Kuantan involving 450 study participants who were selected by using universal sampling method. Level of awareness and practice toward diabetic foot care was assessed using validated self-administered questionnaire. Multiple logistic regressions were performed to identify factors associated with poor foot care practice among the respondents. RESULTS: About $59.6 \%$ of respondents had poor foot care practice and $50.9 \%$ had poor awareness level. Multivariate logistic regression analysis identified that, increasing age (OR 0.97, 95\% Cl: 0.955-0.993) and good awareness towards foot problem (OR 0.43, 95\% Cl: 0.289-0.643) were less likely to have poor foot care practice. However, Malay ethnicity (OR 1.81, 95\% Cl: 1.002-3.271) and obesity (OR 1.9, 95\% Cl: 1.225-2.976) were associated with poor foot care practice after controlling other variables. CONCLUSION: Majority of the respondents had poor foot care practice and poor awareness. Respondents who are older and have better awareness are less likely to have poor foot care practice. Diabetic patients who are Malays and/or obese are predicted to have poor diabetic foot practice and hence must be prioritized for a sustainable patient education and compliance towards foot care practice at primary care level.

KEYWORDS: diabetes mellitus, diabetic foot care practice, primary health clinics, diabetic foots, Malaysia INTRODUCTION

Diabetes mellitus (DM) is a chronic disease that requires lifelong follow-up and management. According to the National Health and Morbidity Survey 2015, the overall prevalence of DM (diagnosed and undiagnosed) among adults of 18 years and above was $17.5 \%$ (95\% Cl: 16.6, 18.3). With increasing prevalence, the morbidity and mortality rate due to DM complications are also currently on the rise. In 2016, an estimated 1.6 million deaths were directly attributable to diabetes. Another 2.2 million deaths were attributable to high blood

Corresponding Author:

Asst. Prof. Dr Azwanis Abdul Hadi,

Department of Family Medicine,

International Islamic University Malaysia,

25200, Kuantan, Pahang, Malaysia.

Tel No : +6095704582

Email : azwanis@iium.edu.my glucose. ${ }^{1}$ Almost half of all deaths occur before the age of 70 years. $^{2}$

Many complications follow DM, which includes lower limb amputations secondary to peripheral neuropathy. ${ }^{2,3}$ Peripheral neuropathy will lead to loss of protective sensation that predispose diabetic patient to foot trauma, which could lead to infection, ulcer and lastly amputation if left untreated. Other risk factors associated with foot problem in DM patients are vascular disease, limited join mobility, abnormal foot pressures, impaired vision, foot deformity, uncontrolled, longer duration of diabetes, and chronic renal failure. ${ }^{4}$ The lack of awareness and knowledge regarding symptoms, risk factors and early screening for diabetic foot remains a major obstacle to the prevention of diabetic foot problems. Hence, identification of the risk factors 
for diabetic foot problems with proper foot care practice plays a very important role in prevention of the said complications.

In a retrospective review done in Kelantan, $66 \%$ of the amputations done were related to diabetic foot problems, with $17.2 \%$ of the sample underwent above knee amputation, while $32.8 \%$ and $50 \%$ underwent below knee amputation and local foot amputation respectively. ${ }^{4}$ As recommended in our Clinical Practice Guideline (CPG) on the Management of Diabetic Foot (second edition), foot care practice is essential in prevention of ulcer formation among diabetic foot at risk. ${ }^{5}$

Among good foot care practices include checking the temperature of water before soaking foot, wearing shoes with socks, inspect shoes for foreign body or torn lining, not sitting with legs crossed, daily foot wash, do not apply moisturizing creams or lotions in between toes, to dry in between toes and daily foot examination. (Good foot care practice enables patient to protect their foot from injury and infection as well as early recognition of foot problem.

Nevertheless in a study done in a hospital in Kuala Terengganu, it was found that $58 \%$ of the respondents had poor foot care knowledge, with $61.8 \%$ had poor foot care practice. ${ }^{6}$ This reflects the need to further assess and improve knowledge and practice especially in the primary setting. More than half of diabetic patients in Malaysia (56\%) are treated in Public Health Clinics as compared to other healthcare facilities in Malaysia. ${ }^{1}$ Therefore, improvement in diabetic care at the primary care level will benefit the patients, as large proportion of diabetics are treated here. Most studies regarding diabetic foot in Malaysia was done in either hospital settings $\mathrm{s}^{4,6}$ or in a university primary care clinic. ${ }^{7}$ Of date, studies on diabetic foot in public primary health clinics are not available.

This study aims to determine the prevalence of poor foot care practice and its associated factors among Type 2 diabetes mellitus (T2DM) patients attending primary health clinics in Kuantan.

\section{METHODS AND MATERIALS}

\section{Study design, population and sampling method}

This is a cross-sectional study which was carried out in four out of ten primary health clinics in Kuantan based on the highest number of registered diabetic patient under the National Diabetes Registry of Malaysia (NDR). The study was conducted from December 2017 until December 2018. This study included registered and consented T2DM patients aged 18 years and above, who are on regular follow up for DM and with good Malay or English literacy. We excluded those with King's Classification of diabetic foot stage three and above as well as those on follow up with Orthopaedics Clinics. Universal sampling was used, where the list of diabetic patients in the four clinics was taken from NDR and eligible respondents were recruited until the required sample size was achieved (450 respondents). Sample size was calculated based on the literature that showed highest prevalence among the variables in this study which was the prevalence of foot at risk (57.7\%). (references)

\section{Study tool}

A validated translated self-administered questionnaire was used. ${ }^{7}$ The questionnaire is designed based on the latest guideline on diabetic foot care Nova Scotia, Canada. It has been pre-tested in a local setting by the previous researcher and the internal reliability (Cronbach alpha) of the questions on awareness of foot problem and practice of foot care showed a reliability result with 0.83 and 0.64 respectively.

The questionnaire consisted of three parts. Part A consisted of sociodemographic data, behavioral factor and clinical data of respondents.

Part B was the questionnaire on respondent's awareness of foot problem (Question 1-4) that includes DM related foot problem, skin changes, neuropathy complication and vascular complication. Respondent's awareness was assessed using 5-point Likert, scale 1 (Not at all aware) to 5 (extremely aware). Awareness level further classified into aware and unaware based on mean score. Those who scored at mean level and more were considered as aware and those who scored below mean were considered as unaware.

Part C was the questionnaire on respondent's foot care practice (Question 5-16). These questions were used to assess the respondent's foot care practice. The practice is assessed by using 'yes' or 'no' responses. Each correct answer was given a score of 
'one' and each wrong answer was given a score of 'zero'. Practice level was further classified into good and poor practice based on mean score. Those who scored at mean or more considered as good practice and vice versa.

\section{Ethical consideration}

Ethical approval to conduct this study was obtained from the Research and Ethics Committee (IREC 2017-078) of the International Islamic University of Malaysia as well as Medical Research Ethic Committee of Malaysia (MREC: NMRR-17-2309-37038). The information sheets regarding the study were distributed and consent was obtained prior to the study.

\section{Statistical Analysis}

Data was then entered and analyzed using IBM SPSS Statistics for Windows version 23.0. Descriptive analysis was used for respondent's socio-demographic data. Categorical variables were summarized into frequency and proportion. Simple logistic regression was used to find the association between categorical data. Multiple logistic regression was used to assess predictors of foot care practice after controlling confounders. Significant level was determined at $95 \%$ confidence intervals with $\mathrm{p}$-value $<0.05$.

\section{RESULTS}

A total of 450 respondents with T2DM from four primary health clinics in Kuantan were involved in this study with a $100 \%$ response rate. The respondents' mean age was of $56.36(S D \pm 10.9)$ years with the youngest being 28 years old and the eldest was 82 years old. Majority of the respondents were females (56.4\%), Malays (85.1\%), married $(93.1 \%)$, with secondary level of education $(53.3 \%$ ) and from low income group (60.7\%).

\section{Respondents' level of practice towards foot care practice}

Table 1 shows the level of practice towards foot care among the respondents. Mean score for practice level is $6.03( \pm 1.89)$ with score $(\geq 6.03)$ taken as good practice. Majority of them $(59.6 \%)$ were found to have poor foot care practice.
Table 1: Level of Practice towards Foot Care among Respondents $(\mathrm{N}=450)$

\begin{tabular}{lcc}
$\begin{array}{l}\text { Practice } \\
\text { Level }\end{array}$ & Frequency & Percentage (\%) \\
\hline Poor & 268 & 59.6 \\
Good & 182 & 40.4 \\
\hline
\end{tabular}

\section{Details of foot care practice of respondents}

Figure 1 and Figure 2 shows the details of foot care practice. It was found that $87.7 \%$ of respondents practiced applying hot water bottle or heating pad to their feet, $80.4 \%$ used medicated products for warts, corns or calluses and $60.2 \%$ walked around barefoot in and outside their houses. Some of the good practices that majority of the respondents carried out are checking the temperature of water before soaking their feet $(55.8 \%)$, wearing shoes with socks $(63.3 \%)$, inspect shoes for foreign body or torn lining $(81.6 \%)$, not sitting with leg crossed (55.6\%), daily feet wash $(93.8 \%)$, did not apply moisturizing creams or lotions in between toes (55.6\%), drying in between toes $74.0 \%$ ), and daily feet examination (62.7\%).

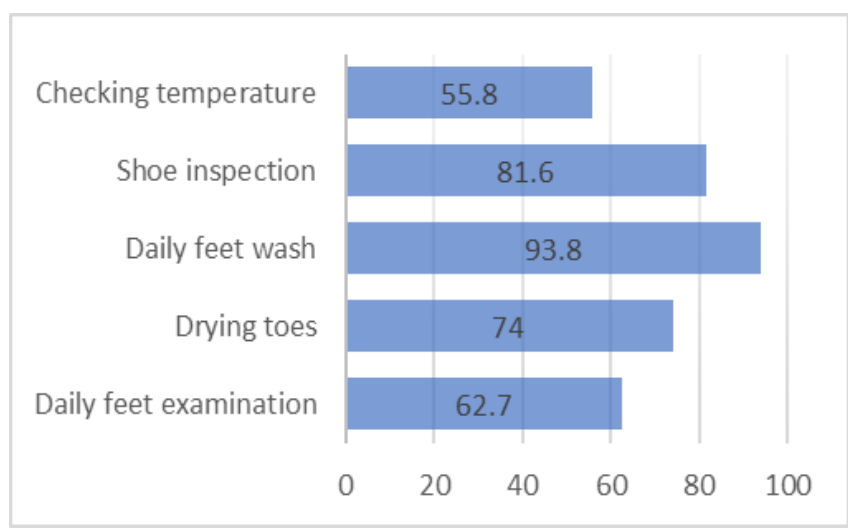

Figure 1: Respondents' Practice of Foot Care $(n=450)$

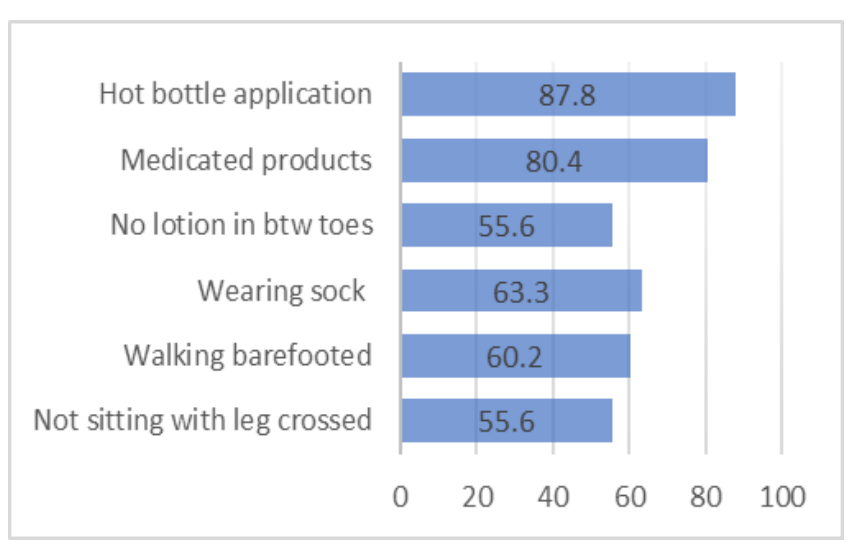

Figure 2: Respondents' Practice of Foot Care $(n=450)$ 


\section{Types of footwear worn by respondents}

Based on Figure 3, majority of respondents (66.2\%) wore flip flops/thongs type of foot wear. A small proportion of them wore pointed shoes $(4.7 \%)$, high heels $(0.7 \%)$, and only $42.2 \%$ of respondents wore broad round shoes.

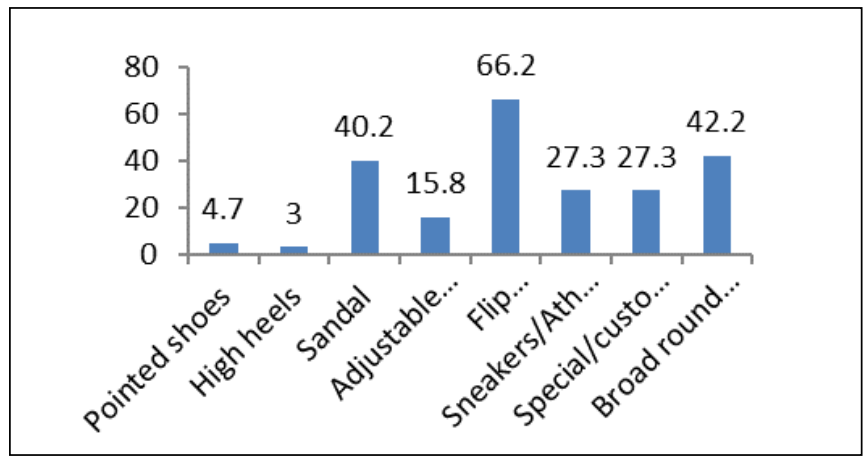

Figure 3: Types of Footwear Worn by Respondents $(n=450)$

\section{Respondents' Level of Awareness towards diabetic foot problem}

Mean score for level of awareness was $12.28( \pm 5.40)$. Table 3 described overall awareness of respondents toward diabetic foot problem based on mean score. Two hundred twenty-nine respondents $(50.9 \%)$ had scored below mean score $(\leq 12.28)$ on diabetic foot problem which indicated poor awareness

Table 3: Level of Awareness towards Diabetic Foot Problem among Respondents $(\mathrm{N}=450)$ according to mean score.

\begin{tabular}{lll}
\hline Level of Awareness & Frequency & Percentage (\%) \\
\hline Poor & 229 & 50.9 \\
Good & 221 & 49.1 \\
\hline
\end{tabular}

Factors associated with diabetic foot care practice (multivariate analysis)

Table 3 shows the background characteristics and awareness level associated with foot care practice. Based on these, the factors that significantly associated with diabetic foot at risk are age and level of awareness.

Factors associated with diabetic foot care practice (multivariate analysis).

In multivariate analysis (Table 4), statistically significant predictive factors identified for foot care practice after controlling other variables were age, race, obesity and awareness level.
Table 3: Foot care practice and its association with background characteristics of respondents and level of awareness by simple logistic regression $(\mathrm{N}=450)$

\begin{tabular}{|c|c|c|c|c|}
\hline & \multicolumn{2}{|c|}{$\begin{array}{l}\text { Foot care Practice } \\
\text { Frequency (\%) }\end{array}$} & \multirow[t]{2}{*}{$\begin{array}{c}\text { Crude OR } \\
(95 \% \mathrm{Cl})\end{array}$} & \multirow[t]{2}{*}{$\begin{array}{c}p- \\
\text { value }\end{array}$} \\
\hline & $\begin{array}{c}\text { Good } \\
(n=309)\end{array}$ & $\begin{array}{c}\text { Poor } \\
(n=141)\end{array}$ & & \\
\hline Age (year) & $\begin{array}{c}54.76 \\
(10.51) a\end{array}$ & $\begin{array}{c}57.45 \\
(11.04)^{\text {a }}\end{array}$ & $\begin{array}{c}0.97 \\
(0.96,0.99)\end{array}$ & 0.011 \\
\hline \multicolumn{5}{|l|}{ Sex } \\
\hline Male & $73(37.2)$ & $123(62.8)$ & \multirow{2}{*}{$\begin{array}{c}1.26(0.87 \\
1.86)\end{array}$} & \multirow[t]{2}{*}{0.220} \\
\hline Female & $109(42.9)$ & $145(57.1)$ & & \\
\hline \multicolumn{5}{|l|}{$\begin{array}{l}\text { Marital } \\
\text { status }\end{array}$} \\
\hline Single & $13(43.3)$ & 7 (56.7) & \multirow[t]{2}{*}{$\begin{array}{c}1.13(0.53 \\
2.4)\end{array}$} & \multirow{2}{*}{0.747} \\
\hline Married & $169(40.3)$ & $250(59.7)$ & & \\
\hline \multicolumn{5}{|l|}{$\begin{array}{l}\text { Educational } \\
\text { level }\end{array}$} \\
\hline $\begin{array}{l}\text { No formal } \\
\text { education }\end{array}$ & $8(29.6)$ & $19(70.4)$ & $\begin{array}{l}0.60(0.25, \\
1.41)\end{array}$ & 0.242 \\
\hline $\begin{array}{l}\text { Formal } \\
\text { education } \\
\text { Income } \\
\text { status }\end{array}$ & $174(41.1)$ & $49(58.9)$ & & \\
\hline Low & $113(41.4)$ & $160(58.6)$ & 1 & \\
\hline Medium & $51(37.0)$ & $87(63.0)$ & $\begin{array}{c}1.21 \\
(0.79-1.83)\end{array}$ & 0.386 \\
\hline High & $18(46.2)$ & $21(53.8)$ & $\begin{array}{c}0.82 \\
(0.42-1.61)\end{array}$ & 0.573 \\
\hline \multicolumn{5}{|l|}{$\begin{array}{l}\text { Smoking } \\
\text { status }\end{array}$} \\
\hline Non smoker & $166(40.6)$ & $243(59.4)$ & $\begin{array}{c}1.06 \\
(0.55,2.06)\end{array}$ & 0.846 \\
\hline Smoker & $16(39.0)$ & $25(61.0)$ & & \\
\hline \multicolumn{5}{|l|}{$\begin{array}{l}\text { Smoking } \\
\text { duration } \\
(\mathrm{N}=41)\end{array}$} \\
\hline years $\leq 10$ & $16(39.0)$ & $11(45.8)$ & $\begin{array}{c}1.06 \\
(0.55,2.06)\end{array}$ & 0.530 \\
\hline $\begin{array}{l}>10 \\
\text { years }\end{array}$ & $8(34.8)$ & $13(54.2)$ & & \\
\hline \multicolumn{5}{|l|}{$\begin{array}{l}\text { Duration of } \\
\text { DM }\end{array}$} \\
\hline years & $8(47.1)$ & $9(52.9)$ & $\begin{array}{c}1.04 \\
(0.65,1.67)\end{array}$ & 0.847 \\
\hline $\begin{array}{l}\quad>10 \\
\text { years }\end{array}$ & $48(15.5)$ & $15(65.2)$ & & \\
\hline \multicolumn{5}{|l|}{ DM Control } \\
\hline Control & $33(34.7)$ & $62(65.3)$ & $\begin{array}{c}0.73 \\
(0.46,1.18)\end{array}$ & 0.203 \\
\hline Uncontrol & $149(42.0)$ & $206(58.0)$ & & \\
\hline \multicolumn{5}{|l|}{$\begin{array}{l}\text { Mode of } \\
\text { treatment }\end{array}$} \\
\hline Non-insulin & $115(40.5)$ & $169(59.3)$ & $\begin{array}{c}1.00 \\
(0.68,1.48)\end{array}$ & 0.987 \\
\hline Insulin & $67(40.4)$ & $99(59.6)$ & & \\
\hline \multicolumn{5}{|l|}{ BMI } \\
\hline Normal & $17(38.6)$ & $27(61.4)$ & 1 & \\
\hline Overweight & $67(48.2)$ & $72(51.8)$ & $\begin{array}{c}0.67 \\
(0.33,1.35)\end{array}$ & 0.269 \\
\hline Obese & $98(36.7)$ & $169(63.3)$ & $\begin{array}{c}1.08 \\
(0.56,2.09)\end{array}$ & 0.806 \\
\hline \multicolumn{5}{|c|}{ Level of awareness } \\
\hline Good & $73(31.9)$ & $156(68.1)$ & $\begin{array}{c}2.08 \\
(1.41,3.05)\end{array}$ & $<0.0001$ \\
\hline Poor & $109(49.3)$ & $112(50.7)$ & & \\
\hline
\end{tabular}


It showed that every one unit increment of age there is $3 \%$ good foot care practice (OR $0.97,95 \% \mathrm{Cl}$ : 0.955-0.993) after controlling other variables. Malay diabetic patient had 1.8 times the odds to have poor foot care as compared to a non-Malay patient (aOR 1.81, 95\% Cl: 1.002-3.271) after controlling for other variables. Respondents who were obese had 1.9 times the odds to have poor foot care practice as compared to those who has normal BMI (aOR 1.9, 95\% $\mathrm{Cl}: 1.225-2.976)$. Respondents who are aware of their foot problem are $57 \%$ have good foot care practice (OR 0.43, 95\% Cl: 0.289-0.643) after controlling for other variables. Other variables like education level and diabetic control does not show significant association with the level of foot care practice.

Table 4: Factors Associated with poor Foot Care Practice $(n=450)$

\begin{tabular}{|c|c|c|c|c|c|}
\hline Variables & B & S.E & aOR & $\begin{array}{c}95 \% \\
\mathrm{Cl}\end{array}$ & $p$-value \\
\hline Age $^{*}$ & -0.027 & 0.01 & 0.97 & $0.95-0.99$ & 0.006 \\
\hline $\begin{array}{l}\text { Race } \\
\text { Non- } \\
\text { Malay } \\
\text { Malay }\end{array}$ & 0.594 & 0.30 & 1.81 & $1.00-3.27$ & 0.049 \\
\hline $\begin{array}{l}\text { Education } \\
\text { Level } \\
\text { No } \\
\text { formal } \\
\text { education } \\
\text { Formal } \\
\text { education }\end{array}$ & -0.660 & 0.46 & 0.52 & $0.21-1.26$ & 0.517 \\
\hline $\begin{array}{l}\text { DM } \\
\text { control } \\
\text { Control } \\
\text { Uncontrolled }\end{array}$ & -0.233 & 0.26 & 0.79 & $0.47-1.31$ & 0.366 \\
\hline $\begin{array}{l}\text { BMI } \\
\text { Normal } \\
\text { Overweight } \\
\text { Obese }\end{array}$ & $\begin{array}{l}0.413 \\
0.647\end{array}$ & $\begin{array}{l}0.35 \\
0.23\end{array}$ & $\begin{array}{l}1.51 \\
1.91\end{array}$ & $\begin{array}{l}0.75-3.02 \\
1.22-2.97\end{array}$ & $\begin{array}{l}0.243 \\
0.004\end{array}$ \\
\hline $\begin{array}{l}\text { Level of } \\
\text { awareness } \\
\text { Unaware } \\
\text { Aware }\end{array}$ & 0.84 & 0.20 & 0.43 & $0.28-.64$ & $<0.001$ \\
\hline $\begin{array}{l}\text { *numerical } \\
\text { The Hosm } \\
\text { p value }-0.3 \\
\text { Classificatio }\end{array}$ & $\begin{array}{l}\text {-Lam } \\
\text { ble - }\end{array}$ & $\begin{array}{l}\text { how } \\
.7 \%\end{array}$ & goodr & of & test, \\
\hline
\end{tabular}

\section{DISCUSSION}

More than half $(59.6 \%)$ of the respondents in this study had poor level of foot care practice. This mostly involved the practice of applying hot bottle or heating pad to their feet $(87.8 \%)$. This kind of practice is dangerous as it will predispose to skin injury especially in patients with peripheral neuropathy. $80.4 \%$ of the respondents used medicated products for warts, corns or calluses. This practice will lead to worsening skin condition, predisposing to injury, inflammation and infection.
The best is they should consult medical personnel for appropriate treatment and follow up. More than half $(60.2 \%)$ of the respondents were walking barefooted either indoors or outdoors. Other studies also showed almost similar result in walking around barefooted (54.8\%). ${ }^{7}$ This might be a cultural influence as most of the respondents were Malays. In the Malay community, walking barefooted, especially indoors, is a common habit. This finding is also similar to a study done at diabetic clinic in a Saudi Hospital. ${ }^{8}$

More than half (55.6\%) of the respondents in this study did not apply moisturizing creams or lotion in between toes. This finding is almost similar with another study which $60 \%$ of the respondents did not practise applying lotion in the interdigital space. ${ }^{9}$ This is essential because applying cream between toes will predispose to fungal infection and could progress to ulcer and infection. ${ }^{10}$

However, this study showed most of the respondents had good foot care practice in terms of daily inspection, washing their feet and drying in between toes. This might be because most of the respondents are Muslims. Indirectly they had to wash their feet at least five times per day during ablution. Similar finding was also observed in other studies. ${ }^{7,9}$ A study in Nigeria showed that less than half of their respondents $(40.9 \%)$ regularly inspect their feet and $46 \%$ regularly wash their feet with warm water. The differences might be contributed by the sociodemographic factors of the country. ${ }^{11}$

According to the Clinical Practice Guideline for Management of Diabetic Foot by Ministry of Health (2018), recommended those with diabetic foot at risk to wear special/custom shoes for diabetic foot, broad round shoes, sneakers/athletic shoes or shoes with adjustable laces, buckles and Velcro. While footwear such as pointed shoes; high heels; sandals and flip flops/thongs are not recommended. ${ }^{5}$ In this study, the types of footwear worn by respondents were also measured. Only $17.8 \%$ of the respondents used special/custom shoes for diabetic foot. Less than half of the respondents (42.2\%) wear broad round shoes; $27.3 \%$ used sneakers/athletic shoes; and $15.8 \%$ of them used shoes with adjustable laces, buckles and Velcro. However, as for the not recommended footwear, only $4.7 \%$ of respondents wore pointed shoes; with $0.7 \%$ wore high heels even though more than half $(66.2 \%)$ wore flip flops/thongs 
and $40.2 \%$ used sandals. These findings are lower as compared to another study in India, which reported usage of slippers (chappals) and sandals with a strap or floaters of $78.7 \%$ and $3.0 \%$ respectively while none $(0.0 \%)$ was wearing shoes or footwear with therapeutic insole. ${ }^{12}$ The higher prevalence of usage of footwear that are not recommended in the mentioned study might be attributed to lower (19.4\%) 'good' foot care practice score in the said study and the fact that in India, the locals prefer to wear an open footwear known as chappals. ${ }^{13}$

Multivariate analysis revealed respondents who were older had good foot care practice (aOR 0.97, 95\% Cl $0.955-0.993)$. This runs in parallel to the findings by previous study conducted in Kuala Terengganu that showed an association between older age group and better foot care practice, though in this study the result was statistically insignificant. ${ }^{6}$ This might be speculated that the older age group have more free time to look after their foot. As well as the availability of diabetic foot care nurse in primary care nowadays, patients are frequently being reminded on foot care at each appointment.

This study also examined race as the factor for diabetic foot care practice, and the result found that the Malays are at significantly higher odds for poorer foot care practice (aOR 1.81, 95\% Cl: 1.002-3.271). This goes against the results by previous study done in Hulu Selangor, that demonstrated diabetic selfcare (which included foot care) to be equal across ethnicities. ${ }^{14}$ This might be attributable to this study's sociodemographic background, as this study's respondents mostly consisted of Malay (85.1\%) with only $8.2 \%$ and $5.8 \%$ of Chinese and Indian ethnicities, while the study in Hulu Selangor had more Chinese and Indian respondents at $12.4 \%$ and $29.6 \%$ respectively. People of Malay ethnicity usually spend most of the time barefooted indoor, thus affecting negatively on one of the aspects of good foot care practice.

Majority of the respondents in this study were obese (59.3\%). This is in line with the report from NMHS 2015 about obesity whereby based on the World Health Organization (WHO) classification, the prevalence of overweight and obesity among adults (18 years and above) were $30.0 \%$ and $17.7 \%$ respectively in 2015 compared to $16.6 \%$ and $4.4 \%$ respectively in 1996. The prevalence of overweight and obesity increased to $80.7 \%$ and $30.2 \%$ respectively in just fewer than two decades. ${ }^{1}$ This predisposed to increasing incidence and prevalence of T2DM in Malaysia and worldwide putting Malaysia as the seventh highest in T2DM and obesity.

Obese Body Mass Index (BMI) was found to be significantly associated in this study, contradicting with a study in Iran which showed no association. ${ }^{16}$ The different outcome might be attributed to the fact that different cut-off values were used in both studies. This study classified BMI into three categories, normal $\left(\leq 22.99 \mathrm{~kg} / \mathrm{m}^{2}\right)$; overweight $(\geq$ $\left.23.00 \mathrm{~kg} / \mathrm{m}^{2}\right)$ and obese $\left(\geq 27.5 \mathrm{~kg} / \mathrm{m}^{2}\right)$ whereas the study in Iran used only $25 \mathrm{~kg} / \mathrm{m}^{2}$ as the cut-off value for BMI. The finding of this study that stated obese to be a risk factor for poor foot care practice might be due to lower adherence to healthy lifestyle among overweight or obese people. ${ }^{17}$

This study showed the level of good awareness among the respondents regarding their foot problems are $49.1 \%$ which is higher compared to the level of awareness by a study done in Pusat Perubatan Universiti Kebangsaan Malaysia (PPUKM) which is $18.7 \%{ }^{7}$ The high level of awareness among diabetic patients in this study could be also because of the presence of a designated diabetic team in primary care clinic nowadays with trained diabetic educator to enhanced education and awareness on diabetic foot care among diabetic patients. Higher level of awareness was found to be significantly associated with better foot care practice, correlating with a study which showed an association between poor diabetic awareness score and poor foot care practice. ${ }^{12}$ This might be explained by the fact that higher awareness will lead to contemplation of the disease, leading to better foot care practice.

\section{CONCLUSION}

It can be concluded that a sustainable patient education and compliance towards practice of foot care at primary care level should be emphasized more to ensure good foot care practice implementation. Our ministry of health is looking forward to empower primary care towards developing a proper foot care team so that a proper foot assessment according to risk factors can be carried out. This is with the aim for early identification of patients with risk factors and timely intervention to prevent unwanted foot complications in the future. 


\section{ACKNOWLEDGEMENT}

This study received the financial support from the International Islamic University Malaysia research initiative grant scheme (RIGS17-046-0639).

\section{AUTHORS' CONTRIBUTION}

All authors have made contribution to this work.

\section{CONFLICTS OF INTEREST}

The authors declare that they have no conflicts of interest

\section{REFERENCES}

1. Institute for Public Health. National Health and Morbidity Survey 2015 (NHMS 2015). Vol. II: Non -Communicable Diseases, Risk Factors \& Other Health Problems. Ministry of health. 2015. 1$291 \mathrm{p}$.

2. Dr. Feisul IM, Dr. Soraya A. NATIONAL DIABETES REGISTRY REPORT.

National_Diabetes_Registry_Report. 2013;Vol_1.

3. World Health Organization. Global Report on Diabetes. Isbn. 2016;978:88.

4. Yusof MI, Sulaiman AR, Muslim DAJ. Diabetic foot complications: A two-year review of limb amputation in a Kelantanese population. Singapore Med J. 2007;48(8):729-32.

5. Ministry of Health. Clinical Practice Guidelines Management of Diabetic Foot (Second Edition). Putrajaya: Malaysian Health Technology Assessment Section (MaHTAS); 2018 p. 14,4045.

6. Muhammad-Lutfi A, Zaraihah M, Anuar-

Ramdhan I. Knowledge and Practice of Diabetic Foot Care in an In- Patient Setting at a Tertiary Medical Center. Malaysian Orthop J. 2014;8

(3):22-6 .

7. Jamani NA. Foot Problem Awareness and Foot Care Among Diabetic Patients Attending Pusat Perubatan Primer Universiti Kebangsaan Malaysia. 2012; (March). Available from: https://www.researchgate.net/ publication/296396205

8. Al-Hariri MT, Al-Enazi AS, Alshammari DM, Bahamdan AS, AL-Khtani SM, Al-Abdulwahab AA.
Descriptive study on the knowledge, attitudes and practices regarding the diabetic foot. $J$ Taibah Univ Med Sci [Internet]. 2017;12(6):492 -6. Available from: http://dx.doi.org/10.1016/ j.jtumed.2017.02.001

9. Hasnain S, Sheikh NH. Knowledge and practices regarding foot care in diabetic patients visiting diabetic clinic in Jinnah Hospital, Lahore. J Pak Med Assoc. 2009;59(10):687-90.

10. Bharara, M. et al., Rajpathak SN, Gunter MJ, Wylie-rosett J, Ho GYF, Kaplan RC, et al. The role of insulin-like growth factor-I and its binding proteins in glucose homeostasis and type 2 diabetes. Diabetes Metab Res Rev. 2009;28(September 2008):3-12.

11. Desalu OO, Salawu FK, Jimoh AK, Adekoya AO, Busari OA, Olokoba AB. Diabetic foot care: self reported knowledge and practice among patients attending three tertiary hospital in Nigeria. Ghana Med J. 2011;45(2):60-5.

12. Saurabh S, Sarkar S, Selvaraj K, Kar S, Kumar $S$, Roy G. Effectiveness of foot care education among people with type 2 diabetes in rural Puducherry, India. Indian J Endocrinol Metab. 2014;18(1):106-10.

13. Chandalia HB, Singh D, Kapoor V, Chandalia $\mathrm{SH}$, Lamba PS. Footwear and foot care knowledge as risk factors for foot problems in Indian diabetics. Int J Diabetes Dev Ctries. 2008;28(4):109-13.

14. Devarajooh C, Chinna K. Depression, distress and self-efficacy: The impact on diabetes selfcare practices. PLoS One. 2017;12(3):1-16.

15. N L, Patel N, Parmar P, Garasiya K, Chaudhary M. Study the foot care practice among diabetic patients in Ahmedabad city, Gujarat. Int J Med Sci Public Heal. 2018;7(5):1.

16. Khamseh ME, Vatankhah N, Baradaran HR. Knowledge and practice of foot care in Iranian people with type 2 diabetes. Int Wound J. 2007;4(4):298-302.

17. Waaijman R, Keukenkamp R, De Haart $M$, Polomski WP, Nollet F, Bus SA. Adherence to wearing prescription custom-made footwear in patients with diabetes at high risk for plantar foot ulceration. Diabetes Care. 2013;36 (6):1613-8. 